\title{
Refracture after locking compression plate removal in displaced midshaft clavicle fractures after bony union: a retrospective study
}

\author{
Ho-Youn Park, Seok-Jung Kim, Yoo-Joon Sur, Jae-Woong Jung, Chae-Gwan Kong \\ Department of Orthopedic Surgery, Uijeongbu St. Mary's Hospital, College of Medicine, The Catholic University of Korea, Uijeongbu, Korea
}

\begin{abstract}
Background: A midshaft clavicle fracture is a common fracture that typically responds well to open reduction and internal fixation (ORIF). However, refracture can occur after implant removal (IR). This study aimed to analyze the rate of refracture and related factors after removal of the locking compression plate (LCP) for displaced midshaft clavicle fractures.

Methods: We retrospectively reviewed the medical records of 201 patients who had undergone ORIF with LCP for midshaft clavicle fractures after IR after bony union from January 2011 to May 2018 at our institute. We evaluated basic demographic characteristics and radiographic parameters. All patients were treated with an LCP for primary fracture. The patients were divided into two groups: a refracture group that experienced a second fracture within 1 year after IR and a no-fracture group.

Results: There were four cases (1.99\%) of refracture; three were treated conservatively, while one was treated surgically. All patients achieved bony union. The average interval between refracture and IR was 64 days (range, 6-210 days). There was a significant difference in classification of fractures (AO Foundation/Orthopaedic Trauma Association [AO/OTA] classification) between the two groups. However, other patient demographics and radiographic measurements between refracture and IR, such as bone diameter, showed no significant difference between the two groups.

Conclusions: This study showed that one in 50 patients suffered from refracture after removal of the LCP. Thus, if patients desire IR, the surgeon should explain that there is a relatively higher possibility of refracture for cases with simple or segmental fractures than for other types of fracture.
\end{abstract}

Keywords: Clavicle; Shaft; Locking compression plate; Removal; Refracture

\section{INTRODUCTION}

Clavicle fracture is a common injury, with an incidence ranging from 29-54 per 100,000; it generally occurs in younger, active in- dividuals $[1,2]$. The peak age of clavicle fracture is between 32 and 34 years [3]. Midshaft fractures account for about $80 \%$ of clavicle fractures, and non-surgical treatments have been recommended in the past. However, the non-surgical treatments de-

Received: January 30, $2021 \quad$ Revised: March 22, $2021 \quad$ Accepted: March 27, 2021

Correspondence to: Chae-Gwan Kong

Department of Orthopedic Surgery, Uijeongbu St. Mary's Hospital, College of Medicine, The Catholic University of Korea, 271 Cheonbo-ro, Uijeongbu 11765 , Korea

Tel: +82-31-820-3947, Fax: +82-31-847-3671, E-mail: gongjae@catholic.ac.kr, ORCID: https://orcid.org/0000-0003-4237-4556

Financial support: None.

Conflict of interest: None. 
scribed by Neer [4] and Rowe [5] in the 1960s have been demonstrated to be clinically and radiologically inferior for displaced midshaft clavicle fractures to surgical treatments like open reduction and internal fixation (ORIF), which show excellent results [6-8]. Commonly used ORIF techniques for midshaft clavicle fractures are plate fixation and intramedullary (IM) nail fixation [1,8-10].

Since the frequency of ORIF increases with clavicle fracture, some studies have reported the issue of implant removal (IR) [11-13]. In some cases, IR is inevitable due to infection, nonunion, or implant breakage. However, in most cases, the decision for IR is based on patient needs or surgeon preference, and the reasons are minor, such as implant-related irritation, discomfort, pain, or limited range of motion. Among these, the most common cause of IR is implant-related irritation due to multifactorial causes, including anatomical location characteristics of the fracture, pain sensitivity, bone quality, surgeon experience, and type of implant used $[6,12,14]$. The rates of irritation range from $9 \%$ to $44 \%$ after plate fixation and from $9 \%$ to $62 \%$ after IM nailing $[6,8,15]$.

A recent prospective study has reported that patients with this kind of discomfort show improved functional outcomes and decreased irritation after IR [16]. However, there is a risk of refracture after IR in patients with midshaft clavicle fracture. The incidence of refracture after IR ranges from $1 \%$ to $7.5 \%[9,10,13,17]$. The purpose of this study was to identify the incidence rate and other factors related to refracture after locking compression plate (LCP) removal for midshaft clavicle fracture after bony union. The results of this study might help surgeons make decisions about IR and prevent refractures.

\section{METHODS}

This study was a retrospective, single-center clinical case series approved by the Institutional Review Board of Uijeongbu St. Mary's Hospital (IRB No. UC21RASI0002). Data were collected from January 2011 to May 2018. We reviewed the medical records of patients who had undergone ORIF with LCP (Synthes, Oberdorf, Switzerland) for midshaft clavicle fracture and an IR procedure after bony union. A simple radiographic examination confirmed union of the fracture. IR was performed upon patient request. Patients who underwent IR for other reasons, such as infection, nonunion, implant loosening, and periprosthetic fracture, were excluded. As no such patients were noted in the present study, none were excluded, and 201 patients were enrolled. The patients were divided into two groups based on refracture after IR surgery: a refracture group $(n=4)$ of patients diagnosed with refracture at the original site within 1 year after IR and a no-fracture group $(n=197)$ of patients who did not show refracture after IR.

Variables were collected by retrospectively reviewing the medical records of all patients enrolled in this study. Data included age, sex, height, body weight, body mass index (BMI), smoking status, interval between initial plate fixation and removal, and characteristics of the refracture. Clavicle anteroposterior (AP) and axial X-rays obtained from the initial fractures until the final follow-up were used for serial radiographic assessments. Bony union of the previous fracture site was confirmed by plain radiographs. The criteria for bony union were as follows: (1) bridging callus formation or complete obliteration of the gap between fracture fragments on AP and axial views, (2) no further migration of implants and no displacement of fracture fragments, and (3) no pain. IR was carried out as follows. Under general anesthesia, the superior approach to the clavicle was used in all cases. Patients were allowed unlimited daily activities from the first day after IR. However, sports activities and lifting of heavy objects were prohibited until 6 weeks postoperatively. The surgery was performed by one orthopedic shoulder surgeon (CGK). Immediate IR postoperative radiography was reviewed to measure clavicle length and diameter at the fracture site. Clavicle length was defined as the length of the virtual line connecting the midpoints of the two ends. Clavicle diameter was measured at the thinnest part of the fracture site. In addition, callus formation at the fracture site was evaluated.

\section{Statistical Analysis}

The baseline characteristics of patients are presented as mean and range or number and percentage. Continuous variables are shown as mean \pm standard deviation (range). Categorical variables are presented as number and percentage. To compare characteristics between groups, a Mann-Whitney U-test was used for continuous variables, and a Fisher's exact test was used for categorical variables. Logistic regression analysis was not carried out because there were only four cases of refracture in this case series. The p-values $<0.05$ were considered significant. All statistical analyses were performed using the SPSS ver. 14.0 (SPSS Inc., Chicago, IL, USA).

\section{RESULTS}

The patient demographics are shown in Table 1 . The mean age at IR was $37.8 \pm 15.5$ years (range, 14-67 years). There were 176 males $(87.6 \%)$ and 25 females (13.4\%). The mean time interval between plate fixation and removal was $14.2 \pm 7.3$ months (range, 
6-66 months). The mean height, weight, and BMI were $169.7 \pm 7.6 \mathrm{~cm}$ (range, 146-188 cm), 69.5 $\pm 12.0 \mathrm{~kg}$ (range, $37-115$ $\mathrm{kg}$ ), and $24.0 \pm 3.3 \mathrm{~kg} / \mathrm{m}^{2}$ (range, $13.4-36.7 \mathrm{~kg} / \mathrm{m}^{2}$ ), respectively. The mean age was $38.0 \pm 15.5$ years (range, 12-67 years) for the no-fracture group and $27.8 \pm 15.0$ years (range, $17-50$ years) for the refracture group $(\mathrm{p}=0.194)$. The refracture group included more women than the no-fracture group (25\% vs. $12.2 \%)$. The mean time interval between fixation and removal was $14.3 \pm 7.3$ months (range, 6-66 months) for the no-fracture group and $10.1 \pm 2.3$ months (range, 7-12 months) for the refracture group $(\mathrm{p}=0.261)$. The mean height, weight, and BMI for the no-fracture group and the refracture group were $169.6 \pm 7.6 \mathrm{~cm}$ (range, $146-188 \mathrm{~cm})$ and $171.8 \pm 2.1 \mathrm{~cm}$ (range, $169-174 \mathrm{~cm})(\mathrm{p}=0.577)$, $69.5 \pm 11.9 \mathrm{~kg}$ (range, $37-115 \mathrm{~kg}$ ) and $65.8 \pm 14.7 \mathrm{~kg}$ (range, 46-80 $\mathrm{kg})(\mathrm{p}=0.532)$, and $24.1 \pm 3.3 \mathrm{~kg} / \mathrm{m}^{2}$ (range, $13.4-36.7 \mathrm{~kg} / \mathrm{m}^{2}$ ) and $22.2 \pm 4.8 \mathrm{~kg} / \mathrm{m}^{2}$ (range, $\left.16.1-27.0 \mathrm{~kg} / \mathrm{m}^{2}\right)(\mathrm{p}=0.269)$, respectively. Age, sex, interval between fixation and removal, height, weight, BMI, and smoking status were not significantly different between the two groups (Table 1).

The rate of refracture was $1.99 \%(n=4)$. The characteristics of patients in the refracture group are shown in Table 2 and Figs.
1-4. These patients demonstrated a wide range of traumatic injuries after IR. Three had trauma history and developed abrupt onset pain and refracture after lifting a heavy object (patient 1) (Fig. 1), falling while playing soccer (patient 2) (Fig. 2), or rising from the floor using the hand (patient 4) (Fig. 4). One of these participants (patient 3) (Fig. 3) had suffered gradual pain for the week before presenting without trauma and being diagnosed with a refracture. One patient (patient 3 ) experienced a refracture at the previous site, while the others had refractures at the empty screw hole. Three patients were treated conservatively with an arm sling. All of them achieved solid bony union by the last follow-up visit. In one patient, the refracture was displaced, and the patient (patient 4) wanted rapid recovery. As a result, re-fixation surgery was performed with an LCP, and bony union was achieved. Repeat removal surgery was performed at 1 year after refixation. There has been no refracture after the second IR.

Radiographic measurements, operative procedures, and fracture classifications are shown in Table 3. The mean clavicular length was $160.0 \pm 11.2 \mathrm{~mm}$ for the no-fracture group and $158.0 \pm 7.4 \mathrm{~mm}$ for the refracture group $(\mathrm{p}=0.853)$. The mean bone diameter was $12.4 \pm 2.1 \mathrm{~mm}$ for the no-fracture group and

Table 1. Demography of the patients

\begin{tabular}{|c|c|c|c|c|}
\hline Variable & Total $(n=201)$ & No fracture $(n=197)$ & Refracture $(\mathrm{n}=4)$ & p-value \\
\hline Age (yr) & $37.8 \pm 15.5$ & $38.0 \pm 15.5$ & $27.8 \pm 15.0$ & 0.194 \\
\hline Sex (male:female) & $176: 25$ & $173: 24$ & $3: 1$ & 0.415 \\
\hline Interval $^{\star}(\mathrm{mo})$ & $14.2 \pm 7.3$ & $14.3 \pm 7.3$ & $10.1 \pm 2.3$ & 0.261 \\
\hline Height $(\mathrm{cm})$ & $169.7 \pm 7.6$ & $169.6 \pm 7.6$ & $171.8 \pm 2.1$ & 0.577 \\
\hline Weight $(\mathrm{kg})$ & $69.5 \pm 12.0$ & $69.5 \pm 11.9$ & $65.8 \pm 14.7$ & 0.532 \\
\hline Body mass index $\left(\mathrm{kg} / \mathrm{m}^{2}\right)$ & $24.0 \pm 3.3$ & $24.1 \pm 3.3$ & $22.2 \pm 4.8$ & 0.269 \\
\hline Smoking & & & & 0.566 \\
\hline No & 131 & 128 & 3 & \\
\hline Yes & 70 & 69 & 1 & \\
\hline
\end{tabular}

Values are presented as mean \pm standard deviation.

${ }^{\star}$ Duration between initial operation and removal operation.

Table 2. Series of four patients in refracture group

\begin{tabular}{|c|c|c|c|c|c|c|c|c|c|c|}
\hline $\begin{array}{l}\text { Patient } \\
\text { no. }\end{array}$ & Sex & $\begin{array}{l}\text { Age at } \\
\text { refracture } \\
(\mathrm{yr})\end{array}$ & $\begin{array}{l}\text { AO/OTA } \\
\text { classifica- } \\
\text { tion }\end{array}$ & $\begin{array}{c}\text { Interval } \\
\text { fixation to IR } \\
(\mathrm{mo})\end{array}$ & $\begin{array}{c}\text { Refracture } \\
\text { time after IR } \\
\text { (day) }\end{array}$ & $\begin{array}{c}\text { Mechanism of } \\
\text { injury } \\
\text { (refracture) }\end{array}$ & $\begin{array}{l}\text { Refracture } \\
\text { site }\end{array}$ & $\begin{array}{l}\text { Refracture } \\
\text { treatment }\end{array}$ & $\begin{array}{c}\text { After } \\
\text { refracture } \\
\text { follow-up (mo) }\end{array}$ & $\begin{array}{l}\text { Final } \\
\text { follow-up } \\
\text { result }\end{array}$ \\
\hline 1 & M & 50 & $\mathrm{C} 2$ & 12 & 11 & Heavy object lifting & Screw hole & $\begin{array}{l}\text { Conserva- } \\
\text { tive }\end{array}$ & 67 & Bone union \\
\hline 2 & M & 17 & A2 & 7 & 210 & Fall down in soccer & Screw hole & $\begin{array}{l}\text { Conserva- } \\
\text { tive }\end{array}$ & 2 & Bone union \\
\hline 3 & $\mathrm{~F}$ & 22 & $\mathrm{~A} 2$ & 10 & 29 & None & $\begin{array}{l}\text { Previous } \\
\text { fracture } \\
\text { site }\end{array}$ & $\begin{array}{l}\text { Conserva- } \\
\text { tive }\end{array}$ & 3 & Bone union \\
\hline 4 & M & 22 & A3 & 11.5 & 6 & $\begin{array}{l}\text { Get up with hand on } \\
\text { the floor }\end{array}$ & Screw hole & ORIF & 22 & Bone union \\
\hline
\end{tabular}

AO/OTA: AO Foundation/Orthopaedic Trauma Association, IR: implant removal, ORIF: open reduction and internal fixation. 

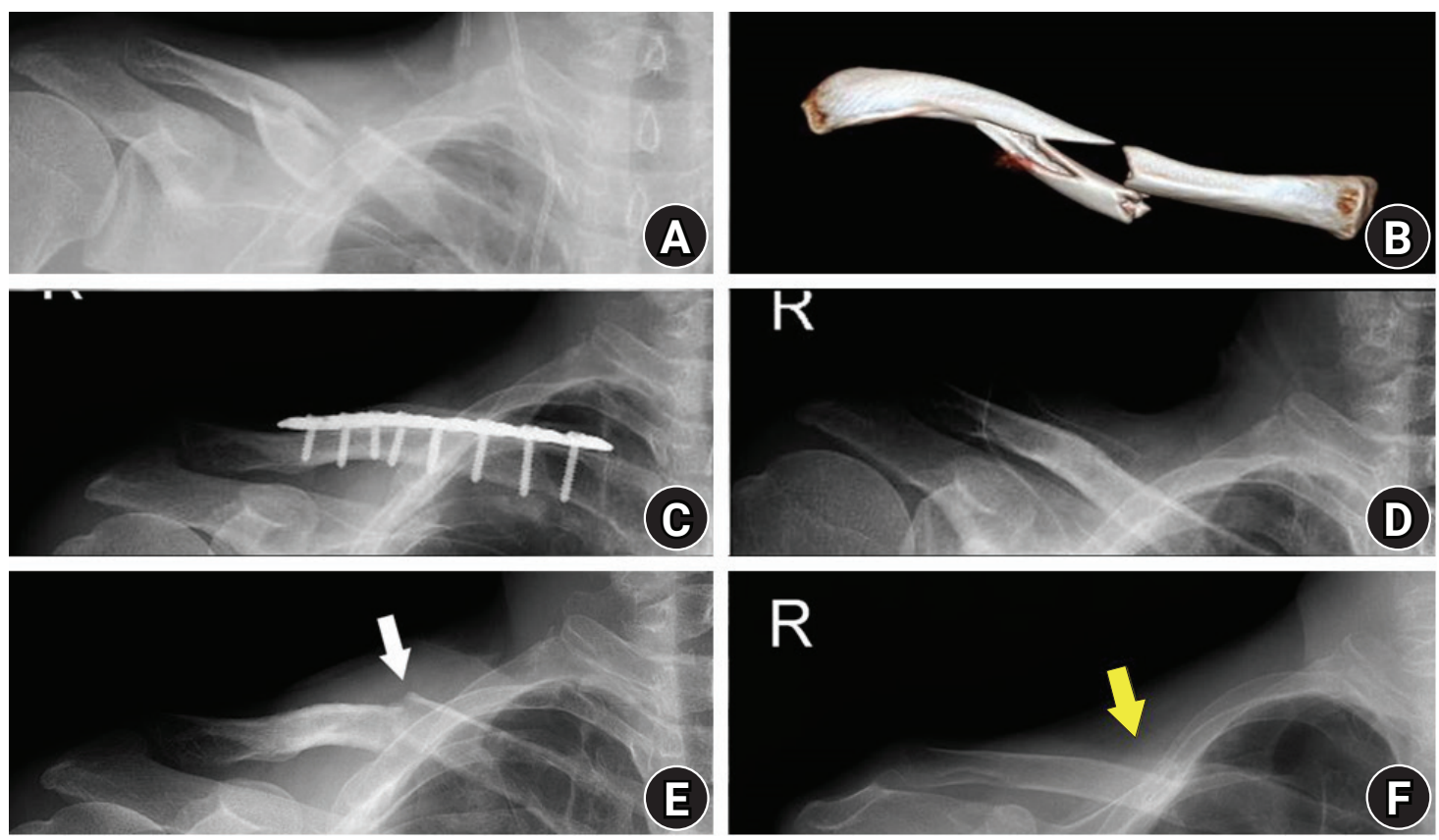

Fig. 1. Imaging of patient 1. X-rays of preoperative (A), three-dimensional computed tomography (B), primary fracture postoperative (C), implant removal (D), refracture at the screw hole (white arrow) (E), refracture fixation postoperative and refracture union (yellow arrow) at the last follow-up (F).
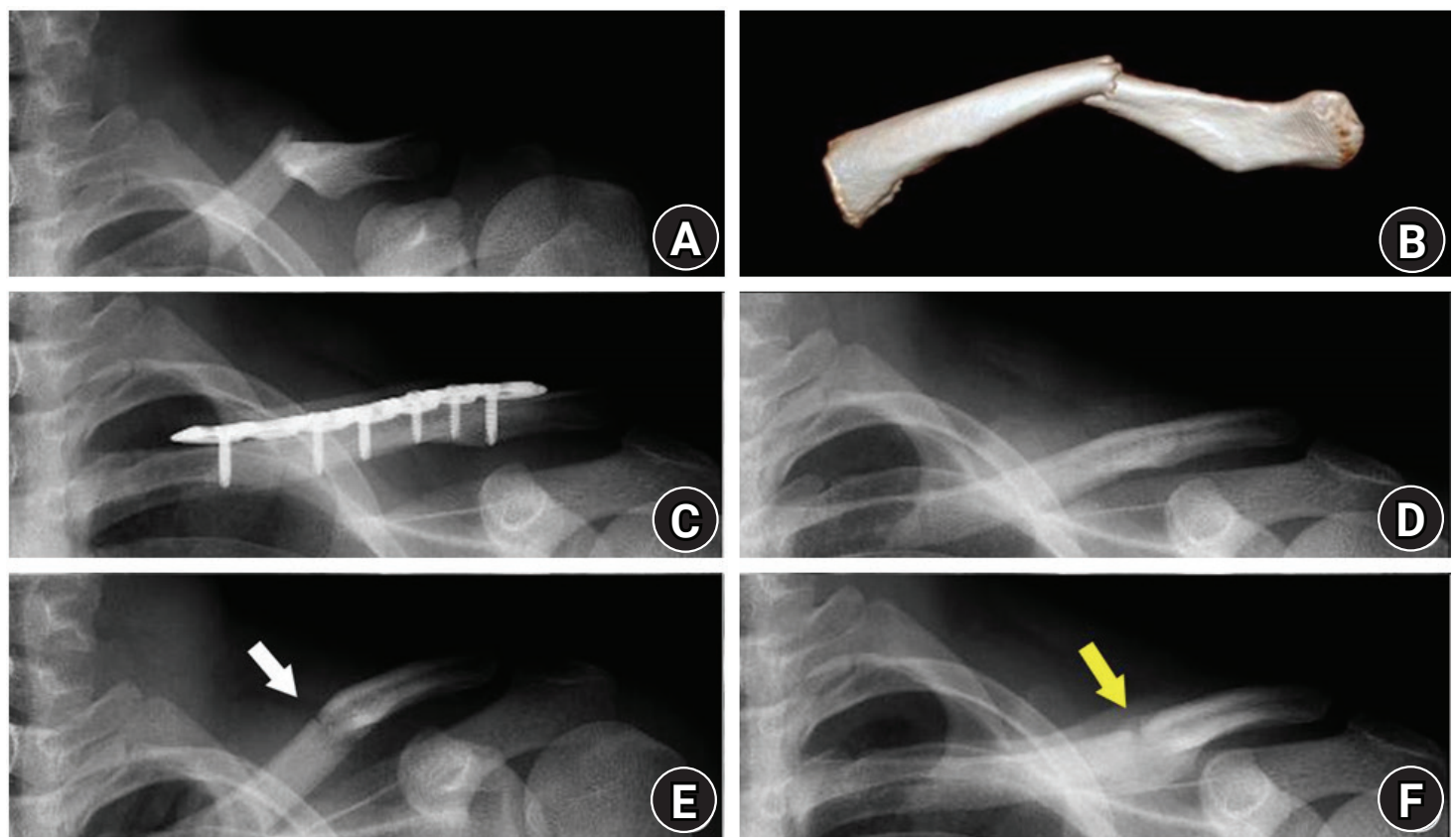

Fig. 2. Imaging of patient 2. X-rays of preoperative (A), three-dimensional computed tomography (B), primary fracture postoperative (C), implant removal (D), refracture at the screw hole (white arrow) (E), refracture fixation postoperative and refracture union (yellow arrow) at the last follow-up (F).

$11.2 \pm 2.2 \mathrm{~mm}$ in the refracture group $(\mathrm{p}=0.229)$. These differences were not statistically significant. Wires were used in 132 patients $(65.7 \%)$, and interfragmentary screws were used in 40 patients (20\%). The frequency rates for use of wire or interfragmentary screws and the presence of callus were not significantly different between the two groups. All patients underwent initial fracture surgery using LCP. After analyzing the two groups based on fracture classification, the most common fracture pattern was AO Foundation/Orthopaedic Trauma Association (AO/OTA) 15.2B (wedge fracture: $n=141,70.1 \%$ ). There were no patients in 

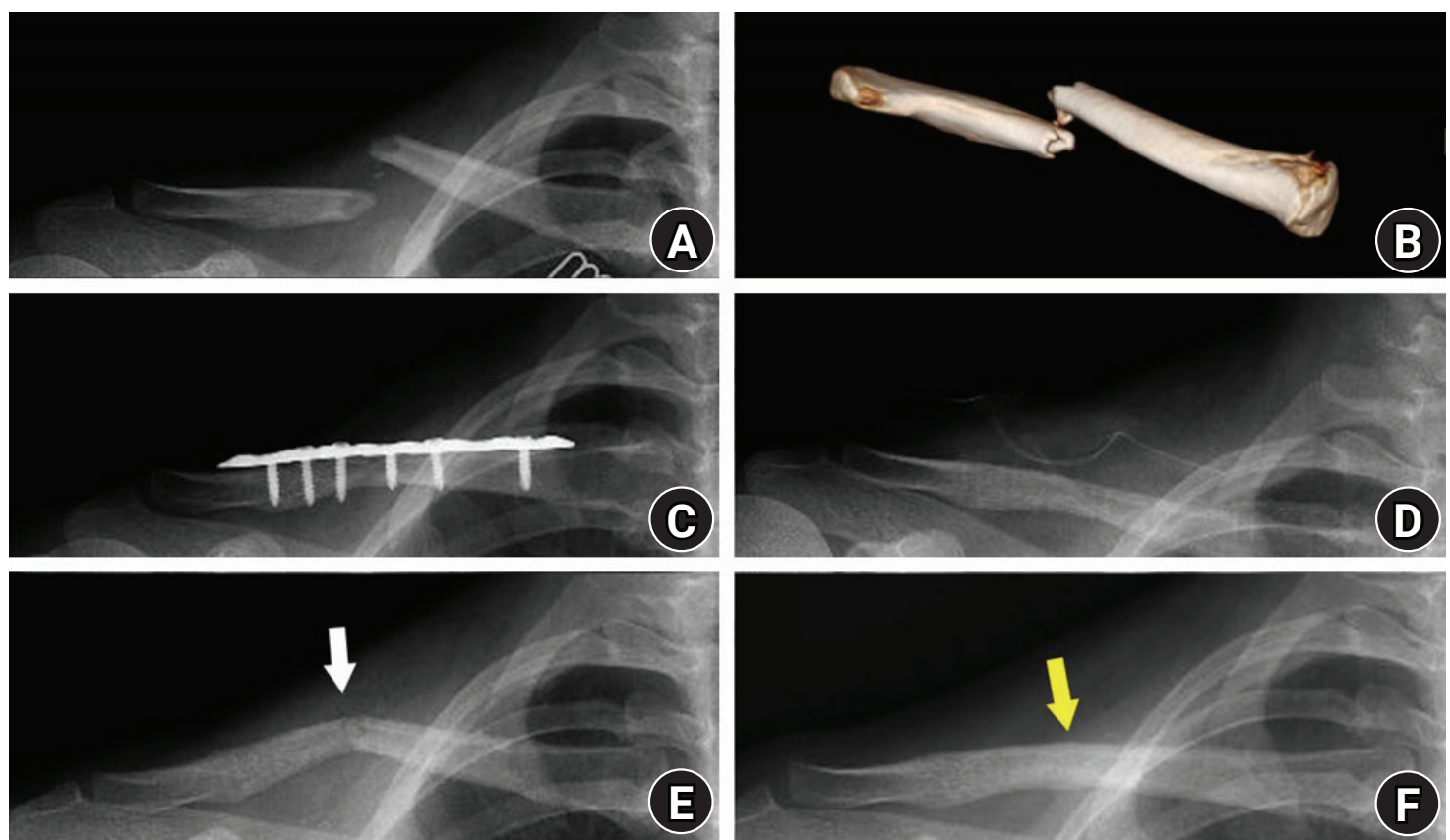

Fig. 3. Imaging of patient 3. X-rays of preoperative (A), three-dimensional computed tomography (B), primary fracture postoperative (C), implant removal (D), refracture at the screw hole (white arrow) (E), refracture fixation postoperative and refracture union (yellow arrow) at the last follow-up (F).
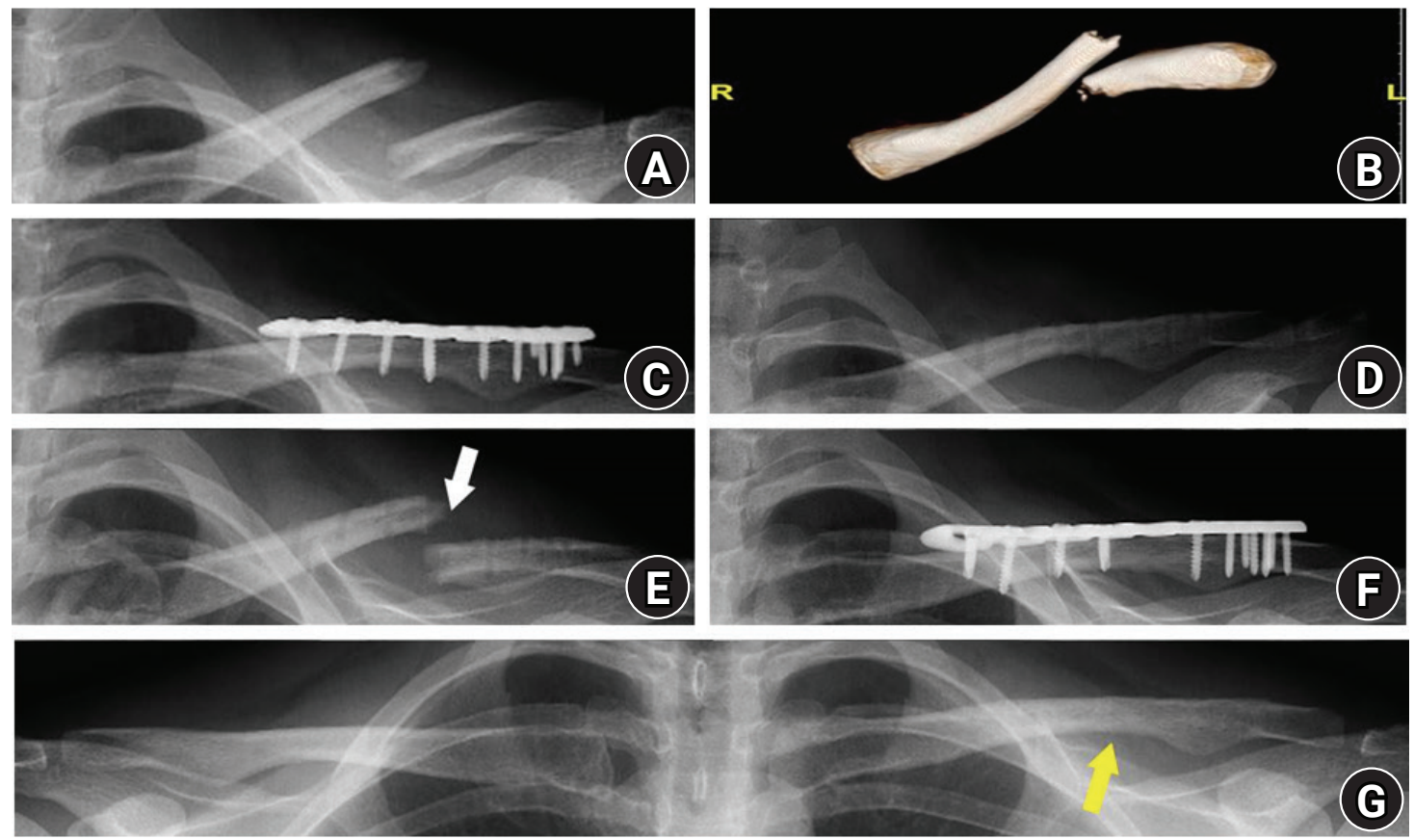

Fig. 4. Imaging of patient 4. X-rays of preoperative (A), three-dimensional computed tomography (B), primary fracture postoperative (C), implant removal (D), refracture at the screw hole (white arrow) (E), refracture fixation postoperative (F), refracture union (yellow arrow) at the last follow-up $(\mathrm{G})$.

the refracture group with $\mathrm{AO}$ type $\mathrm{B}$ fracture (three type A fractures and one type $\mathrm{C}$ fracture). The difference between the two groups was statistically significant $(\mathrm{p}=0.005)$.

\section{DISCUSSION}

This study aimed to analyze the rate of refracture after LCP re- 
Table 3. Radiographic measurements, operative procedures, and fracture classification

\begin{tabular}{|c|c|c|c|c|}
\hline Variable & Total $(n=201)$ & No fracture $(n=197)$ & Refracture $(\mathrm{n}=4)$ & p-value \\
\hline Length (mm) & $157.0 \pm 11.1$ & $160.0 \pm 11.2$ & $158.0 \pm 7.4$ & 0.853 \\
\hline Diameter $(\mathrm{mm})$ & $12.4 \pm 2.1$ & $12.4 \pm 2.1$ & $11.2 \pm 2.2$ & 0.229 \\
\hline Callus & & & & 0.299 \\
\hline None & 149 & 145 & 4 & \\
\hline Callus & 52 & 52 & 0 & \\
\hline Wire & & & & 0.425 \\
\hline None & 69 & 67 & 2 & \\
\hline Wiring & 132 & 130 & 2 & \\
\hline Interfragmentary screw & & & & 0.409 \\
\hline None & 161 & 157 & 4 & \\
\hline Fixation & 40 & 40 & 0 & \\
\hline AO/OTA classification type & & & & $0.005^{\star}$ \\
\hline A & 55 & 52 & 3 & \\
\hline $\mathrm{B}$ & 141 & 141 & 0 & \\
\hline $\mathrm{C}$ & 5 & 4 & 1 & \\
\hline
\end{tabular}

Values are presented as mean \pm standard deviation.

AO/OTA: AO Foundation/Orthopaedic Trauma Association.

*Statistically significant.

moval for midshaft clavicle fracture following bony union. The overall refracture rate was $1.99 \%(4 / 201)$ in this study. Only one factor, AO/OTA fracture classification, had a statistically significant difference between the refracture group and the no-fracture group. A previous study [13] reported an overall refracture rate of $7.2 \%$, with female and lower BMI as risk factors for refracture. However, we did not identify differences in these factors between the two groups in this study. According to our analysis, patient demographics were similar in these two groups. The main differences between the present study and the previous were number of included participants (201 in the present study vs. 278 in the previous) and surgical techniques (for example, plate type and requirement for wire or interfragmentary screws) used in the initial surgery. Due to our small number of patients and very low rate of refracture (1.99\%), we could not analyze the risk factors statistically (logistic regression analysis). Further studies are needed to determine whether differences in rate of refractures might have been caused by factors other than those mentioned above.

In this study, the only difference between the two groups was classification of the initial fracture. Fractures were classified using the AO/OTA classification, of which the wedge type fracture (B type) was most common. However, no patient in the refracture group had this fracture type but showed one segmental fracture (C2 fracture, in patient 2) and three simple fractures (two $\mathrm{A} 2$ and one A1 fractures). In patient 2, a relatively severe trauma occurred 210 days after IR. We hesitated to include this case in the present study, but it was included after confirming that the area of refracture was the previous screw hole. Wedge-type fractures have a separate fragment and required additional wiring or interfragmentary screw fixation was required in $87.9 \%$ of patients in this study. As a result, it was estimated that the broad fracture area would have been newly healed at the wedge or fragment location. In the case of a simple or segmental fracture, we anticipated that the fracture sites might be narrow or vertical and vulnerable to impacts or shear forces if complete union was not achieved. For this reason, we concluded that the two groups differed in classification of fractures.

Patients who underwent IR surgery in this study had various reasons for requesting IR. This surgery was performed if a simple $\mathrm{X}$-ray confirmed bony union. As in general cases, this procedure was performed around 1 year after the initial fracture surgery depending on patient circumstances. In one patient (patient 3) with refracture at the fracture site and who had experienced no minor trauma, X-rays after removal surgery showed complete bony union. However, refracture occurred 10 months after IR. Although a simple radiographic examination indicated that the fracture site was healed, IR might have been performed before complete bony union. In addition, the strength of the bony union might not have been sufficiently determined using simple radiography.

The average removal interval in the refracture group was shorter than in the no-fracture group, although the difference was not significant. Therefore, it cannot be recommended to remove the plate before the fracture site is completely healed. Patients need sufficient attention and postoperative care if removal 
surgery is scheduled within 1 year of the initial fracture surgery. One study [18] reported that upper extremity fracture IR should be performed no less than 18 months after the primary surgery. Our study showed that average removal time was shorter in the refracture group, although this difference was not significant. Thus, if removal time is delayed for more than 1 year, the possibility of refracture or characteristics after IR could be different. Further studies will be needed to confirm our findings.

In this study, three patients with refracture obtained bony union with conservative treatments. One patient underwent surgical treatment with an autologous iliac bone graft due to displacement of the refracture site, with repeat removal surgery performed at one 1 year after revision surgery. No refracture occurred after the second removal surgery. In patients who developed refracture, bony union had been confirmed before IR. Therefore, we thought that the refracture site might have had biological potential for bone healing, as in treatment of primary midshaft clavicle fractures. Thus, the degree of displacement should be used to decide whether to perform revision surgery. In this type of revision, there is no clear guideline for bone grafting. Fixation alone without a bone graft could result in bony union of the fracture. However, bone grafting should be considered as a procedure that allows definite bony union. One patient (patient 4) in this study underwent an autogenous iliac bone graft during refixation surgery. Further study is needed to determine whether bone graft is required for all refractures of the midshaft clavicle after IR.

This study had several weaknesses. First, the reason for the IR procedure was not studied, though the most common reason for reoperation after mid-clavicle shaft fracture was isolated IR. According to a recent systematic review, $0 \%-53 \%$ of all clavicle ORIF plates are removed eventually [7]. In the present study, $51.8 \%$ of patients who underwent primary clavicle fracture procedure underwent IR during the same period. The reasons for the IR were not investigated in this study, although no IR was due to major complications such as infection, nonunion, metallic failure, or loosening. Second, radiographic parameters were evaluated using only simple X-rays. Since the shape of the clavicle is not perfectly cylindrical on plain radiographs, more accurate thickness measurements would have been possible if additional computed tomographic tests had been conducted. Finally, the number of patients included in the study was small. Refracture was not a common complication, occurring in only $1.99 \%$ of all patients. Four refracture cases were not enough to statistically analyze the risk factors. Therefore, further studies with more participants and other statistical methods are needed to reduce the chance of bias, increase statistical confidence, and analyze the characteristics of refractures following midshaft clavicle fracture after bony union.

This study showed that one in 50 patients suffered refracture after removal of LCP following ORIF of midshaft clavicle fracture. Before performing IR, surgeons should explain the relatively higher possibility of refracture in cases with simple or segmental fracture than in those with other types of fractures.

\section{ORCID}

Ho-Youn Park

Seok-Jung Kim

Yoo-Joon Sur

Jae-Woong Jung

Chae-Gwan Kong https://orcid.org/0000-0001-8781-5533

https://orcid.org/0000-0002-9116-8786

https://orcid.org/0000-0003-0090-9970

https://orcid.org/0000-0002-7817-2422

https://orcid.org/0000-0003-4237-4556

\section{REFERENCES}

1. Khan LA, Bradnock TJ, Scott C, Robinson CM. Fractures of the clavicle. J Bone Joint Surg Am 2009;91:447-60.

2. Nordqvist A, Petersson C. The incidence of fractures of the clavicle. Clin Orthop Relat Res 1994;(300):127-32.

3. Nowak J, Mallmin H, Larsson S. The aetiology and epidemiology of clavicular fractures: a prospective study during a two-year period in Uppsala, Sweden. Injury 2000;31:353-8.

4. NEER CS 2nd. Nonunion of the clavicle. J Am Med Assoc 1960;172:1006-11.

5. Rowe CR. An atlas of anatomy and treatment of midclavicular fractures. Clin Orthop Relat Res 1968;58:29-42.

6. Canadian Orthopaedic Trauma Society. Nonoperative treatment compared with plate fixation of displaced midshaft clavicular fractures: a multicenter, randomized clinical trial. J Bone Joint Surg Am 2007;89:1-10.

7. Wijdicks FJ, Van der Meijden OA, Millett PJ, Verleisdonk EJ, Houwert RM. Systematic review of the complications of plate fixation of clavicle fractures. Arch Orthop Trauma Surg 2012;132:617-25.

8. van der Meijden OA, Houwert RM, Hulsmans M, et al. Operative treatment of dislocated midshaft clavicular fractures: plate or intramedullary nail fixation? A randomized controlled trial. J Bone Joint Surg Am 2015;97:613-9.

9. Russo R, Visconti V, Lorini S, Lombardi LV. Displaced comminuted midshaft clavicle fractures: use of Mennen plate fixation system. J Trauma 2007;63:951-4.

10. VanBeek C, Boselli KJ, Cadet ER, Ahmad CS, Levine WN. Precontoured plating of clavicle fractures: decreased hardware-related complications. Clin Orthop Relat Res 2011;469:3337-43. 
11. Leroux T, Wasserstein D, Henry P, et al. Rate of and risk factors for reoperations after open reduction and internal fixation of midshaft clavicle fractures: a population-based study in Ontario, Canada. J Bone Joint Surg Am 2014;96:1119-25.

12. Hulsmans MH, van Heijl M, Houwert RM, et al. High irritation and removal rates after plate or nail fixation in patients with displaced midshaft clavicle fractures. Clin Orthop Relat Res 2017;475:532-9.

13. Tsai SW, Ma HH, Hsu FW, et al. Risk factors for refracture after plate removal for midshaft clavicle fracture after bone union. J Orthop Surg Res 2019;14:457.

14. McKee RC, Whelan DB, Schemitsch EH, McKee MD. Operative versus nonoperative care of displaced midshaft clavicular fractures: a meta-analysis of randomized clinical trials. J Bone Joint Surg Am 2012;94:675-84.

15. Andrade-Silva FB, Kojima KE, Joeris A, Santos Silva J, Mattar R
Jr. Single, superiorly placed reconstruction plate compared with flexible intramedullary nailing for midshaft clavicular fractures: a prospective, randomized controlled trial. J Bone Joint Surg Am 2015;97:620-6.

16. Wurm M, Beirer M, Zyskowski M, et al. Does implant removal of superior clavicle plate osteosynthesis affect the functional outcome: a prospective trial. Arch Orthop Trauma Surg 2020 Nov 1 [Epub]. https://doi.org/10.1007/s00402-020-03669-z.

17. Böstman O, Manninen M, Pihlajamäki H. Complications of plate fixation in fresh displaced midclavicular fractures. J Trauma 1997;43:778-83.

18. Yao CK, Lin KC, Tarng YW, Chang WN, Renn JH. Removal of forearm plate leads to a high risk of refracture: decision regarding implant removal after fixation of the forearm and analysis of risk factors of refracture. Arch Orthop Trauma Surg 2014;134: 1691-7. 